\title{
Quality of care of patients with type-2 diabetes in Galicia (NW Spain) [OBTEDIGA project]
}

\author{
J. I. Vidal Pardo, T. R. Pérez Castro, X. L. López Álvarez, F. J. García Soidán, M. I. \\ Santiago Pérez, J. Muñiz
}

\begin{abstract}
Summary
Aims: The aim of this study was to describe the degree of compliance of agreed practices with reference to primary care patients with Type 2 diabetes of 40 years old and older in Galicia (NW Spain).

Methods: A total of 108 primary care physicians were selected at random from the totality of doctors. Each physician selected 30 patients at random from their patients suffering from diabetes of 40 years old or older. External observers gathered information from each patient's medical record regarding their characteristics, condition and degree of compliance of selected indicators of good practice.

Results: Group of physicians participated in this study had a mean age of 50 years (standard deviation $=3.9$ ); $48 \%$ of them were females; and $17.5 \%$ involved in medical residents training. A total of 3078 diabetic patients were included in the study: mean age $=69$ years $(\mathrm{SD}=10.9), 47.6 \%$ women, presence of high blood pressure $(72 \%)$, hypercholesterolaemia (56\%), and regular smokers (10.3\%). Compliance with selected indicators such as foot examination (14\%), ophthalmological examination (30.6\%), abdominal circumference measurement $(6.1 \%)$, measurement of total or LDL-cholesterol (78.1), blood pressure measurement (84.8), glycosylated haemoglobin measurement $<7 \%(54.3 \%)$ was observed. Adequate monitoring in cases of high blood pressure and hypercholesterolaemia were $34.2 \%$ and $27.4 \%$, respectively. Variability between physicians differs according to the different indicators, with interquartile range for compliance of between 16.4 and $66 \%$.

Conclusions: There is a wide margin for improvement in the adaptation of clinical practice to recommendations for diabetic patients. The large variation existing in certain indicators would suggest that certain control objectives are less demanding than advisable in those that comply least, while low compliance and low variability in other indicators point to structural problems or unsatisfactory training of doctors.
\end{abstract}

\section{Introduction}

Type-2 diabetes is currently one the of the greatest public health problems, because of its associated complications (diabetic nephropathy, neuropathy and retinopathy, as well as cardiovascular disease) $(1,2)$. Estimates indicate that the burden of this disease will increase worldwide, turning it into a global pandemia during the course of the present century, affecting 366 million people worldwide by the year 2.030 (3). Ageing populations, obesity and sedentary lifestyles are some of its main causes in the developed world (4).

In Spain, estimates of its prevalence range from $7 \%$ to $16 \%$, depending on the geographical area and diagnostic criteria used, highlighting the fact that undiagnosed diabetes could constitute a further $3.7 \%$. Incidence ranges between 8.1 and 10.8 per thousand inhabitants/year (5-10).

A strict control of glucose levels is associated with a reduction of its main complications (11-15), which has led to the development of different recommendations and treatment guides issued by scientific organisations (16). Even so, the degree of compliance to these in clinical practice is far from optimal in such patients (17). This disparity has been previously observed in the case of a large number of chronic conditions, especially in the cardiovascular area, and within very diverse environments (among different countries, among areas within a country, in hospitals and primary care, etc.) and is one of those factors responsible for failure to reach therapeutic targets $(15,18)$. The gap existing between recommendations and clinical practice varies between different areas and conditions, and we do not currently dispose of information concerning the situation of care for diabetic patients (19) in Galicia. The aim of this study was to describe the current degree of compliance and variation between agreed practices in the care of diabetic patients of 40-years old and over in primary care in Galicia. This information will be of assistance in defining specific improvement strategies. 


\section{Methods}

A cross-sectional study was carried out on a sample of primary care physicians randomly selected by stratified random sampling (by administrative area, seven in Galicia) among all primary care physicians working in Galicia (North West of Spain). The objective was to include 30 diabetic patients randomly selected from the relationship of type 2 diabetic patients of every participating physician.

\section{Exclusion criteria}

All doctors who expected to change their practices while the study was conducted (because of reallocation) and those attending very small populations ( $<500$ people) because of the small number of diabetic patients expected were excluded. Patients under 40 years of age and/or with a recent diagnosis of diabetes $(<1$ year) were also excluded.

Physicians were invited to participate by letter and the data collection was performed in 2007-2008.

\section{Variables}

Each physician provided information on general aspects of her/his professional practice. Information regarding each patient was collected from medical records by outside observers (nursing staff) previously trained by the research team. Data collected included characteristics of doctors and their work environment, characteristics of patients and their condition, personal and family history of disease and indicators of process quality and diabetes outcome (Table 1).

Table 1. Process and result indicators* analysed

Process indicators

Proportion of individuals whose glycated haemoglobin (HbA1c) has been measured at least once in the past 6 months

Proportion of individuals who have had at least one ophthalmological exploration in the past 2 years, out of all patients included in the study

Proportion of individuals who have undergone at least one microalbuminuria assessment in last 12 months, out of all patients under 75 years of age without established nephropathy

Proportion of individuals who have undergone a complete foot examination at least once in the last year, out of all patients included in the survey

Proportion of individuals who have their cardiovascular risk factors measured in the last 12 months:

Blood pressure

Serum cholesterol

Result indicators

Proportion of individuals, with glycosylated haemoglobin (HbA1c) below 7\%. Denominator: all patients surveyed; patients with that measurement

Proportion of individuals with a specific monitoring and/or treatment plan for high blood pressure or high cholesterol levels among those who need it:

High blood pressure: monitoring and treatment plan needed if the blood pressure being higher than $130 / 80 \mathrm{mmHg}$

Dyslipemia: monitoring and treatment plan needed if total cholesterol is over $200 \mathrm{mg} / \mathrm{dl}$ or LDL-cholesterol over $100 \mathrm{mg} / \mathrm{dl}$

*From ‘Plan de Saúde 2007-10’ (19).

\section{Definition of variables}

Body mass index (BMI) was calculated using the following formula: Weight $(\mathrm{kg}) / \mathrm{height}$ (in metres) ${ }^{2}$. We classify BMI values into 'non-obese' (BMI between 18.5 and 24.9), 'overweight' (BMI between 25 and 29.9) and 'obese' (BMI $\geq 30$ ). Central Obesity criteria was as follows: A) Adult Treatment Panel-III (ATP-III): waist circumference $\geq 102 \mathrm{~cm}$ in men and $\geq 88 \mathrm{~cm}$ in women; B) International Diabetes Federation (IDF): waist circumference $\geq 94 \mathrm{~cm}$ in men and $\geq 80$ in women. 


\section{Sample size considerations}

The study was powered to offer a precision to estimate a proportion of $\pm 2.6 \%$ in the most unfavourable case $(\mathrm{p}=\mathrm{q}=50 \%)$ with a confidence level of $95 \%$ and adjusting for the effect of our study design, which was assumed to be 1.5 .

\section{Data analysis}

Numerical variables are summarised by average and standard deviation and categorical variables by frequency distribution. The percentages of compliance with quality indicators for each participating physician were plotted for each indicator separately. Variability among physicians for each indicator and between the different indicators is represented by a box-and-whisker plot.

\section{Ethics}

All patients received detailed explanation of the study and signed an informed consent. The protocol study was approved by the Ethics Committee of Clinical Research of Galicia.

\section{Results}

Of the total of 2120 primary care physicians working in Galicia, 295 were invited to participate and 114 were agreed to participate $(38.6 \%)$. Six physicians were excluded because of failure to meet inclusion criteria, leaving 108 who carried out their professional activity in 84 different health centres who included 3078 type- 2 diabetic patients.

The demographic and professional characteristics of the doctors involved, and of the total primary care physicians in the area of Galicia are shown in Table 2. There is no nursing consultation in $2.6 \%$ of them; $17.5 \%$ of the participating physicians were involved in medical residents training. In general, although no marked differences are observed between the sample and the population in terms of age, gender and years of professional activity in the last place of work, differences do appear in the proportion of participating teaching practices.

Table 2. Characteristics of primary care physicians participating compared with the total number of physicians in Galicia (results in percentage unless otherwise stated)

\begin{tabular}{lll}
\hline & Study subjects $(n=108)$ & Total Galicia† $(n=2120)$ \\
\hline & & 51.3 (n.d.a.) \\
Average age (SD) in years & $49.9(3.9)$ & 47.1 \\
Gender (Female) & 48.2 & n.d.a. \\
Professional activity, in years. Average (SD) & $23.6(5.3)$ & 13.1 (n.d.a.) \\
$\quad$ Total years & $11.6(9.3)$ & n.d.a. \\
$\quad$ In current position & 94 & 11 \\
Nursing consultation & 34.3 & 9.3 \\
MIR* training performed in their health centre & 17.5 & n.d.a. \\
Tutor of FCM residents & 91.8 & n.d.a. \\
Performs diabetological education & & n.d.a. \\
Education performed by $(n=99)$ & 23.3 & n.d.a. \\
$\quad$ Physician & 6.7 & \\
$\quad$ Nurse & 70 & \\
$\quad$ Both & & \\
\end{tabular}

SD, standard deviation; n.d.a., no data available; FCM, family and community medicine.

*MIR: Professionals who were trained as Interim Medical Residents in family and community medicine (FCM) for at least 3 years after graduating in Medicine.

$\dagger$ Data provided by the Department of Health of the Xunta de Galicia (regional government). 
Table 3 shows socio-demographic characteristics and personal history of disease of the patients. These patients are old $(80.8 \%$ are over 60 years old) and show a high prevalence of risk factors such as hypertension and hypercholesterolaemia.

Table 3. Characteristics of patients included (results in percentage unless otherwise stated)

\begin{tabular}{ll} 
Average age $(\mathrm{SD})(n=3078)$ & $69.3(10.9)$ \\
Women $(n=3077)$ & 47.6 \\
Educational level $(n=470)$ & 4 \\
Graduates & 10.9 \\
Secondary school & 76.6 \\
Primary school & 8.5 \\
Little or none & \\
Employment status $(n=2702)$ & 20.6 \\
Paid work & 4.9 \\
Unpaid work & 74.5 \\
Pensioner & 72.1 \\
HBP $(n=3009)$ & 88.8 \\
Dietetic treatment & 92.2 \\
Pharmacological treatment & 56.2 \\
Hypercholesterolemia $(n=2964)$ & 88.5 \\
Dietetic treatment & 84.8 \\
Pharmacological treatment & \\
Smoking habit $(n=2859)$ & \\
& \\
Smoker & 10.3 \\
Ex-smoker & 17.9 \\
Non-smoker & 71.8 \\
Peripheral artery disease $($ PAD) & 5.2 \\
Cerebrovascular Accident $(\mathrm{CVA})$ & 6.6 \\
Heart failure & 7.3 \\
Prior revascularisation & 7.6 \\
Angina pectoris & 5.2 \\
Myocardial infarction & 5.6 \\
Relatives with sudden death or IHD & 15.4 \\
& \\
\hline
\end{tabular}

SD, standard deviation; HBP, high blood pressure (if mean arterial pressure is above 130/80); CVA, stroke, IHD, ischaemic heart disease.

Important information to establish self-care programmes (such as educational level) is lacking from the clinical history (84.7\% do not provide this information).

The characteristics of the disease and its treatment are shown in Table 4 while obesity-related information index is shown in Table 5. Very few patients $(n=188 ; 6.1 \%)$ have information on waist circumference. 
Table 4. Characteristics and treatment of the diabetes (results in percentage terms unless otherwise stated)

\begin{tabular}{ll}
\hline & \\
Years since diagnosis of diabetes. Average $(\mathrm{SD})(n=1703)$ & $8.4(6.3)$ \\
Complications & 9.2 \\
$\quad$ Retinopathy $(n=3078)$ & 5.1 \\
Nephropathy $(n=3078)$ & 3.1 \\
$\quad$ Neuropathy $(n=3078)$ & 30.1 \\
Self-analysis $(n=2895)$ & 88 \\
Diet (affirmative): $(n=2707)$ & 85.6 \\
$\quad$ Qualitative $(n=2707)$ & 2.8 \\
$\quad$ Quantitative $(n=2707)$ & 11.5 \\
$\quad$ Both $(n=3078)$ & $1,544.4(182)$ \\
$\quad$ Calories. Average (SD) $(n=380)$ & 76.5 \\
Oral antidiabetic drugs $(n=3021)$ & 16.2 \\
Insulin $(n=2994)$ & $7.2(2.0)$ \\
HbA1c. Average $(\mathrm{SD})(n=1971)$ & $191.4(41.8)$ \\
Total cholesterol $(\mathrm{mg} / \mathrm{dl})$. Average (SD) $(n=2322)^{*}$ & $116.7(36.7)$ \\
LDL cholesterol $(\mathrm{mg} / \mathrm{dl})$. Average (SD) $(n=1899)^{*}$ & \\
\hline
\end{tabular}

SD, standard deviation; LDL, low density lipoprotein.

*Only analyses less than 1 year old are included.

Table 5. Distribution of body mass index and central obesity (results in percentage terms unless otherwise stated)

\begin{tabular}{lll}
\hline & Males & Females \\
\hline & & \\
Body mass index $\left(\mathrm{kg} / \mathrm{m}^{2}\right)$. Average (SD) $n=2267$ & $30.2(4.2)$ & $31.4(5.9)$ \\
Waist circumference $(\mathrm{cm})$. Average (SD) $n=188$ & $104.8(11.3)$ & $99.6(11.4)$ \\
Non-obese (BMI: $\left.18.5-24.9 \mathrm{~kg} / \mathrm{m}^{2}\right)$ & 43.2 & 31.5 \\
Overweight $\left(\mathrm{BMI}: 25-29.9 \mathrm{~kg} / \mathrm{m}^{2}\right)$ & 8.2 & 10.2 \\
Obesity (BMI: $\left.\geq 30 \mathrm{~kg} / \mathrm{m}^{2}\right)$ & 48.6 & 58.3 \\
Central obesity (ATP-III*) & 57.7 & 90.9 \\
Central obesity (IDF $\dagger)$ & 85.6 & 96.1 \\
& & \\
\hline
\end{tabular}

SD, standard deviation; BMI, body mass index.

*ATP-III criteria: waist circumference in men $\geq 102$ and $\geq 88 \mathrm{~cm}$ in women.

$\dagger$ IDF criteria: waist circumference in men $\geq 94$ and $\geq 80 \mathrm{~cm}$ in women.

Table 6 presents results referring to the degree of compliance in the period of time set for each indicator. The degree of compliance was higher on total or LDL-cholesterol measurement, recommendation of exercise and physical examination (weight, height and blood pressure). Last year, of all the diabetics, only $30.6 \%$ had undergone an eye examination and $14.4 \%$ a foot examination. With reference to result indicators, $34.2 \%$ of diabetics with high blood pressure were put on a specific monitoring and/or a treatment plan. In cases of dyslipidemia (average total cholesterol measurements $>200$ or LDL cholesterol > $100 \mathrm{mg} / \mathrm{dl}$ ), the percentage with a change in diagnosis and/or treatment was $27.4 \%$. 
Table 6. Process and result indicators in all 3078 patients (results in percentage)

Process indicators: (at last one measurement in the period indicated)

Glycosylated Haemoglobin measurement in last 6 month

Micro-albuminuria measurement in last 12 months:

Overall

$<75$ years old without nephropathy

39

Foot examination (measuring at least peripheral pulses)in last 12 months $\quad 14.4$

Eye examination in last 24 months

30.6

Complete physical examination in last 12 months:

Weight

Height

80.6

Blood Pressure

84.8

Waist circumference

6.1

Total cholesterol or LDL-cholesterol measurement in last 12 months

Recommendation to have physical exercise (in last 12 months)

Result indicators (last 6 months)

Glycosylated haemoglobin:

$<7 \%$ in patients with that measurement $(n=1592)$

$<7 \%$ in all patients $\quad 28$

High blood pressure. If mean arterial pressure (MAP) $>130 / 80 \mathrm{mmHg}$

Specific monitoring and/or treatment plan $(n=1909)$

Dyslipemia. If total cholesterol > 200 or LDL > $100 \mathrm{mg} / \mathrm{dl}$

Change of diagnosis and/or treatment $(n=1746)$

LDL, low density lipoprotein.

The figures 1 and 2 show, among the 108 physicians in the study, the compliance with the quality indicators presented in Table 1 plus an adicional one related with recommendations of physical activity. The triangles represent the percentage of compliance for each doctor and the horizontal line represent the overall rate of compliance calculated with the data of all patients. The indicators that are best complied with are measurement of blood pressure (84.4\%) and of total cholesterol or LDL-cholesterol $(78.1 \%)$, recommendation of physical exercise $(68.8 \%)$ and measurement of glycosylated haemoglobin $(52.3 \%)$. The compliance of the rest of the indicators is below $40 \%$. We can also see, in these figures, the variability in compliance between physicians, which is quantified for each indicator in Figure 3. 


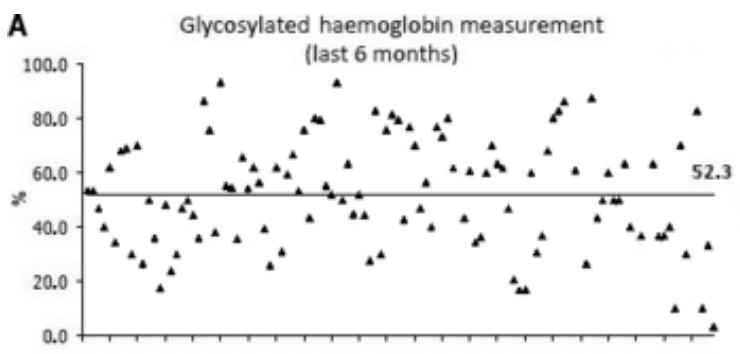

B Recommendation to have physical exercise (last 12 months)
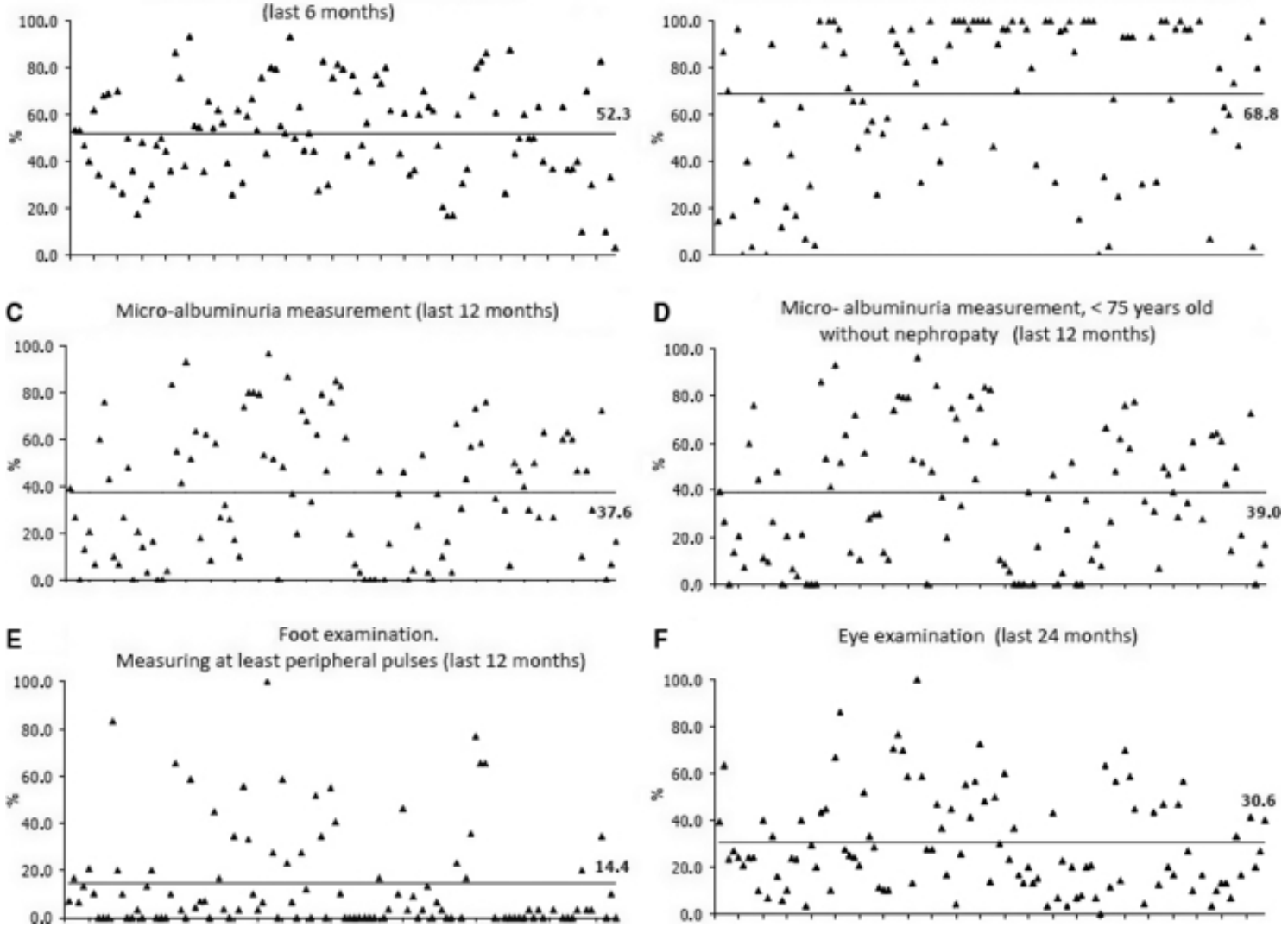

Figure 1. Variability in clinical practice among physicians in six selected indicators. Legend: The triangles represent the percentage of compliance for each physician $(n=108)$. The horizontal line represents the overall percentage of compliance calculated with data from all patients

G

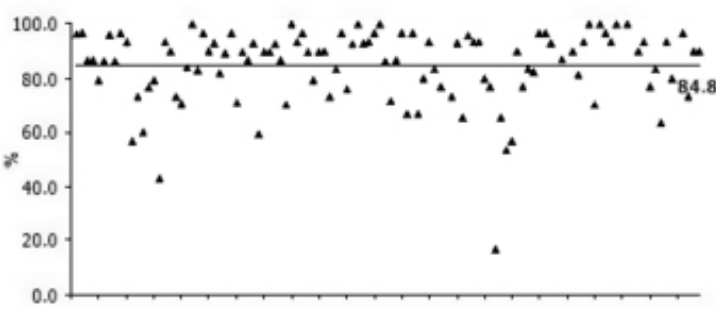

I

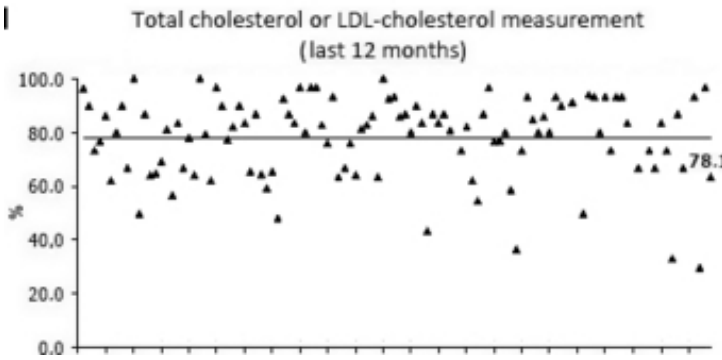

H If mean average pressure is above $130 / 80$, is there a specific monitoring and/or treatment plan? (last 6 months) $(n=1.909)$

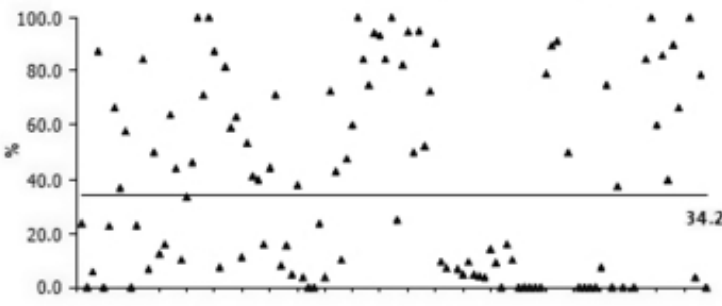

J If total cholesterol is $>200 \mathrm{mg} / \mathrm{dl}$ or LDL $>100 \mathrm{mg} / \mathrm{dl}$, did this cause diagnosis and/or treatment to change? (last 6 months) $(n=1.746)$

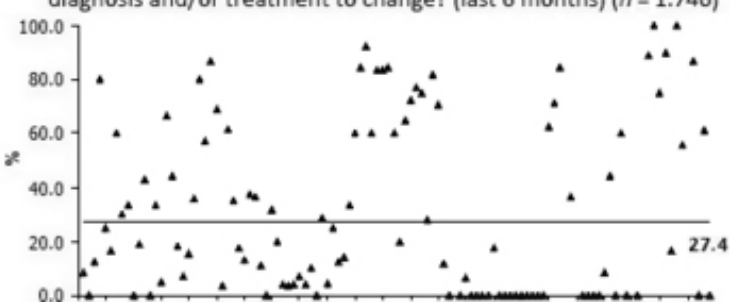

Figure 2. Variability in clinical practice among physician on four selected indicators. Legend: The triangles represent the percentage of compliance for each physician $(n=108)$. The horizontal line represents the overall percentage of compliance calculated with data from all patients 


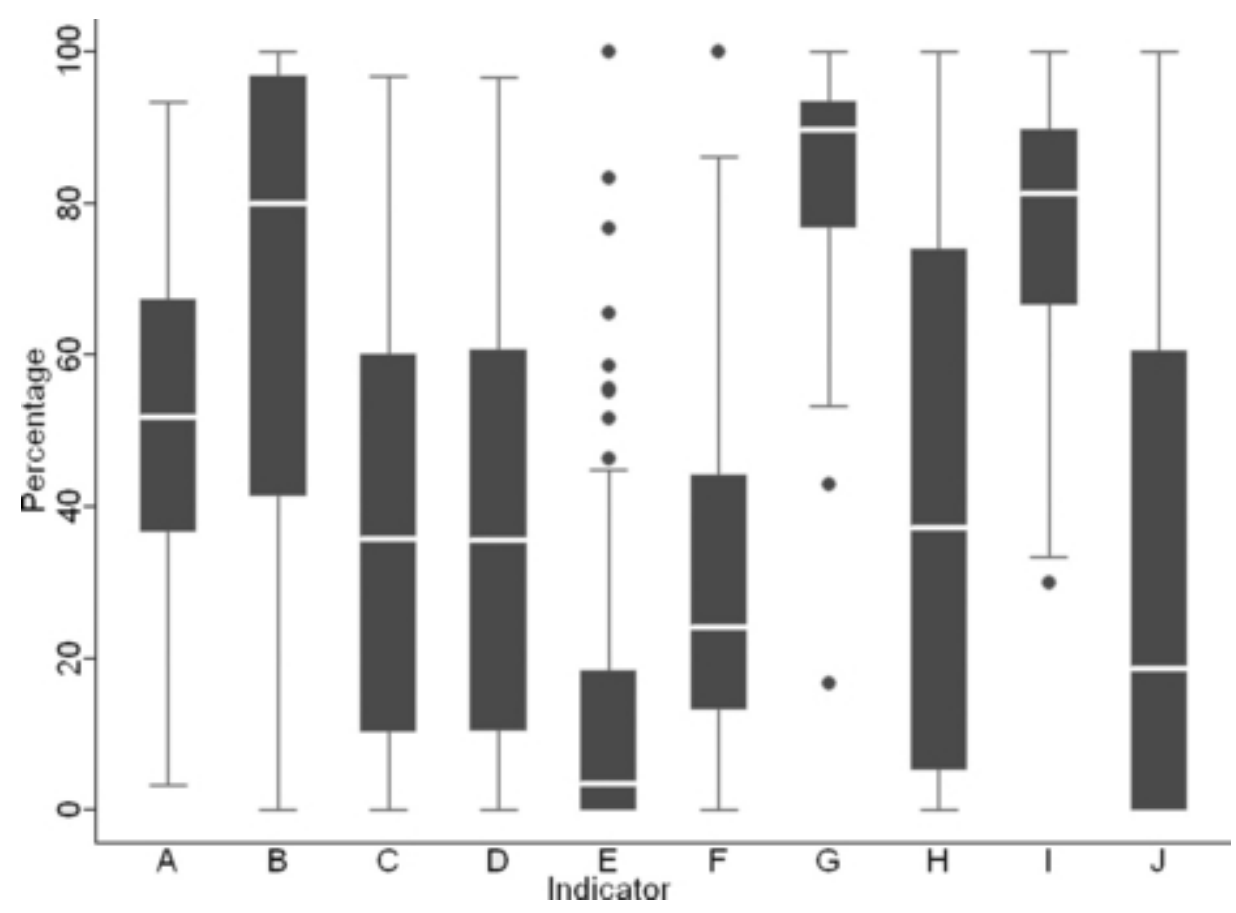

Figure 3. Box plot for percentage of compliance among doctors, by indicator. Note: Each capital letter indicated on the horizontal axis represents the corresponding indicator shown in Figures 1 and 2, marked with the same letter and order. Interquartile range (R): $\mathrm{A}=30.3 ; \mathrm{B}=50.8 ; \mathrm{C}=48.7 ; \mathrm{D}=50.1 ; \mathrm{E}=19.2 ; \mathrm{F}=30.0 ; \mathrm{G}=16.4 ; \mathrm{H}=66.0 ; \mathrm{I}=22.3 ; \mathrm{J}=60.0$

\section{Discussion}

This study shows, within a large sample of primary care physicians in Galicia, the gap between current recommendations for the care of diabetic patients and real care. It also provides valuable information to identify areas in which improvement is most needed.

The characteristics of the physicians included largely resemble those of other primary care physicians in Galicia, with the participation of professionals working in different types of health centres, with their distribution and type of activity which is representative of the care network and is thus non-selective.

The profile of the diabetics included displays a high average age, low level of education (mostly primary or even lower) and a high percentage of patients who are retired from work. With regard to the prevalence of cardiovascular disease and risk factors, our figures are comparable with those described previously and that have led to the implementation of numerous programmes to prevent complications in type 2 diabetes $(20,21)$. The figures related to excess weight and obesity are consistent with other studies both in the general population of our environment (22) and in other diabetic patients in various populations studied $(17,23,24)$.

The proportion of insulinised patients monitored in primary care in our environment does not differ from that described in other publications $(17,24-28)$.

Although great differences exist among various national and international recommendations in managing diabetes (16,29-32), our chosen quality indicators are among those usually used to evaluate quality of care and forms part of Galicia's 'Health Plan 2006-10 for Diabetes' (19).

The degree of compliance with some of these indicators (Table 6), such as weight, blood pressure and lipid profile is similar to that of other studies in different environments $(24,33,34)$. In other process indicators, the results are far from both the ideal and from the situation reflected in other studies, and it is therefore necessary to design specific actions for improvement. This is the case of eye examination, foot examination or measurement of microalbuminuria $(17,24,26,34)$. These three indicators are very important for the early detection of macro- and micro-vascular complications in diabetics and, therefore, useful for the prevention of cardiovascular disease, renal failure, blindness and amputations (35), as is also shown in the Saint Vincent declaration (36). In other items, such as 6-monthly HbA1c measurement, or population of diabetic patients within glycaemic control targets (Hbalc $<7$ ), the situation is also far from ideal and there is a lot of room for improvement. 
The prevalence of central obesity is based on just 188 patients (6.1\% of the total), which reflects how infrequently we use a procedure which is both simple and widely supported in the literature as a predictor of cardiovascular events (37-41).

Although acceptable levels for the quality criteria of measurement of blood pressure and lipid profile were obtained, those with high levels are not frequently engaged in specific follow-up and control programmes as recommended. This also reflects the existence of 'clinical inertia', which is also found in other studies (42-44): despite the lack of positive outcomes (i.e. adequate blood pressure or lipids control), there is a resistance to modify the therapeutic approach. To overcome this inertia, it will not only be necessary to make this information known, but also to develop automated systems that can change attitudes. The type of action chosen is important to achieve results in this area (45).

This study objectifies the problem of the great variability in clinical practice among physicians, a variability that would be reflected, in theory, in clinical outcomes. The selected indicators can be classified into three groups, based on the degree of compliance and its variability among physicians: the least variable ones (divided in turn into two major groups: high and low compliance) and the most variable ones. Measurement of blood pressure and total or LDL cholesterol have low variability and high compliance level, while the complete foot examination and eye test have little variability and a low level of compliance. The rest of the indicators are within the high variability group. This has important implications when corrective measures are incorporated for the target population. The low variability in clinical practice in low performance indicators suggests the necessity of developing education and training procedures for professionals, while the great variability found in different indicators demonstrates the different care practices and suggest physician or practice related causes.

One of the possible limitations of our study is the initial response rate of physicians (39\% of all those randomly selected and invited to the initial meeting by letter). Although there are not great differences with the general population of physicians, it can be argued that there is a bias for the participation of those more motivated, either with the disease (diabetes) or with quality of health programmes. In any case, this would probably tend to overestimate the quality of care observed.

The survey may have been affected by the fact that they knew they were going to be investigated, which might have led to a change in their clinical practice, although this is rather unlikely as doctors had little time to make such changes.

In conclusion, there is ample room for improvement in Galicia as far as the adaptation of clinical practice to accepted recommendations for the treatment of diabetic patients is concerned.

The main deficiencies found are those regarding the early identification of micro-vascular complications (feet, eyes and kidneys). These deficiencies, which are widespread among all physicians taking part, are very important because the health cost of diabetes is directly related to the time the disease evolves, and can be primarily attributed to the treatment of complications during the course of the disease (46). Therefore, the prevention of complications is a key aspect in the design of care for diabetic patients.

We need to improve the identification of specific either physician-related factors or place of workrelated the adherence to recommendations, to be able to incorporate specific measures in those indicators with higher variability.

These results can be used directly by the primary care physicians and health administrators in Galicia to identify and highlight individual items that need improvement in the care of the diabetic patient and introduce corrections where needed. The use of these results in the rest of Spain should be only orientative, because although a common healthcare system is in place in Spain, the indicators considered are dependent on the health priorities set by local health administrators and therefore, amenable to differ among Autonomous Communities within Spain.

\section{Authors' contributions}

- Vidal Pardo, JI: Head investigator, study concept, participation in study design, fund-raising, doctors' training and recruitment, writing of manuscript and critical revision of article.

- Pérez Castro, TR: Doctors' training and recruitment, fieldwork coordination in monitoring of patients, writing of manuscript and critical revision of article.

- López Álvarez, XL: Doctors' training and recruitment, writing of manuscript and critical revision of the article.

- García Soidán, FJ: Doctors' training and recruitment, critical revision of article.

- Santiago Pérez, MI: Statistical data analysis and critical revision of article.

- Muñiz, J: Study concept, participation in its design, fund raising, doctors' training and recruitment, writing of manuscript and critical revision of article. 
All the authors have read and given their approval to the final manuscript.

\section{Acknowledgements}

This study was partially financed with an unrestricted grant from Merck Sharp \& Dohme (MSD)-Spain and the Fundación Escola Galega de Administración Sanitaria (FEGAS). Neither MSD nor FEGAS participated in the study design, data analysis or the preparation of this manuscript. J. Muñiz is a research from the RECAVA network (Instituto de Salud Carlos III. Madrid)

\section{References}

1. Goday A. [Epidemiology of diabetes and its non-coronary complications]. Rev Esp Cardiol 2002; 55: 657-70.

2 Massi-Benedetti M, Board C-A. The cost of diabetes type II in Europe: the CODE-2 study. Diabetologia 2002; 45: S1-4.

3 Wild S, Roglic G, Green A et al. Global prevalence of diabetes: estimates for the year 2000 and projections for 2030. Diabetes Care 2004; 27: 1047-53.

4 International Diabetes Federation. IDF Diabetes Atlas, 4th edn. Brussels, Belgium: International Diabetes Federation, 2009.

5 Catalá Bauset M, Girbés Borrás J, Lluch Verdú I et al. Estudio de prevalencia de diabetes en la Comunidad Valenciana. Av Diabetol 2006; 22(Suppl.): 13.

6 Castell C, Tresserras R, Serra J et al. Prevalence of diabetes in Catalonia (Spain): an oral glucose tolerance testbased population study. Diabetes Res Clin Pract 1999; 43: 33-40.

7 Soriguer-Escofet F, Esteva I, Rojo-Martinez G et al. Prevalence of latent autoimmune diabetes of adults (LADA) in Southern Spain. Diabetes Res Clin Pract 2002; 56: 213-20.

8 Valdés S, Botas P, Delgado E, Díaz Cadórniga F. Mortality risk in spanish adults with diagnosed diabetes, undiagnosed diabetes or pre-diabetes. The Asturias study 1998-2004. Rev Esp Cardiol 2009; 62: 528-34.

9 Muñiz J, Cordido F, Rodriguez IL, Beiras AC. Effect of the application of the new diagnostic criteria of diabetes mellitus in the prevalence estimates and diagnostic level in the general population. European J Publ Health 1999; 9: $149-51$.

10 Muñiz J, Hervada J, Juane R et al. Prevalence of diabetes mellitus in the population aged 40-69 years in Galicia, northwest Spain. Diabetes Res Clin Pract 1995; 30: 137-42.

11 Nathan D, Cleary P, Backlund J et al. Intensive diabetes treatment and cardiovascular disease in patients with type 1 diabetes. N Engl J Med 2005; 353: 2643-53.

12 Holman R, Paul S, Bethel M et al. 10-year follow-up of intensive glucose control in type 2 diabetes. N Engl J Med 2008; 359: 1577-89.

13 Gerstein H, Miller M, Byington R et al. Effects of intensive glucose lowering in type 2 diabetes. N Engl J Med 2008; 358: 2545-59.

14 Duckworth W, Abraira C, Moritz T et al. Glucose control and vascular complications in veterans with type 2 diabetes. N Engl J Med 2009; 360: 129-39.

15 Patel A, MacMahon S, Chalmers J et al. Intensive blood glucose control and vascular outcomes in patients with type 2 diabetes. N Engl J Med 2008; 358: 2560-72.

16 American Diabetes Association. Standards of medical care for patients with diabetes mellitus. Diabetes Care 2007; 30: S4-41.

17 Orozco-Beltrán D, Gil-Guillen V, Quirce F et al. Control of diabetes and cardiovascular risk factors in patients with type 2 diabetes in primary care. The gap between guidelines and reality in Spain. Int J Clin Pract 2007; 61: 909-15.

18 Hibbard J. What can we say about the impact of public reporting? Inconsistent execution yields variable results. Ann Intern Med 2008; 148: 160-1.

19 Plan de Saúde 2006-2010. Santiago de Compostela: Xunta de Galicia. Consellería de Sanidade. Dirección Xeral de Aseguramento e Planificación Sanitaria 2006:73-86.

20 Wingard D, Barrett-Connor E, Scheidt-Nave C, McPhillips J. Prevalence of cardiovascular and renal complications in older adults with normal or impaired glucose tolerance or NIDDM. A population-based study. Diabetes Care 1993; 16: 1022-5.

21 Turner R, Stratton I, Horton V et al. UKPDS 25: autoantibodies to islet-cell cytoplasm and glutamic acid decarboxylase for prediction of insulin requirement in type 2 diabetes. UK Prospective Diabetes Study Group. Lancet 1997; 350: 1288-93.

22 Muñiz García J, Pérez Castro T, Hervada Vidal X et al. Enquisa sobre os hábitos alimentarios da poboación adulta galega, 2007. Santiago de Compostela: Dirección Xeral de Saúde Pública. Consellería de Sanidade. Xunta de Galicia 2008

23 Benito López P, García Mayor R, Puig Domingo M et al. [Pathological characteristics of patients with diabetes mellitus type 2, in Spanish Primary Care]. Rev Clin Esp 2004; 204: 18-24.

24 Franch Nadal J, Artola Menéndez S, Diez Espino J et al. [The evolution of quality care indicators of patients with type 2 diabetes in the Spanish primary care (1996-2007). The RedGEDAPS quality of care program.]. Med Clin (Barc) 2010; 135: 600-7. 
25 Benito López P, García Mayor R, Puig Domingo M et al. [Pathological characteristics of patients with diabetes mellitus type 2, in Spanish Primary Care]. Rev Clin Esp 2004; 204: 18-24.

26 de la Calle H, Costa A, Díez-Espino J et al. [Evaluation on the compliance of the metabolic control aims in outpatients with type 2 diabetes mellitus in Spain The TranSTAR study]. Med Clin (Barc) 2003; 120: 446-50.

27 Arroyo J, Badía X, de la Calle H et al. [Management of type 2 diabetic patients in primary care in Spain]. Med Clin (Barc) 2005; 125: 166-72.

28 Grupo ELIPSE. Effectiveness of control of cardiovascular risk factors in type 2 diabetic population of Ciudad Real province. Rev Clin Esp 2005; 205: 218-22.

29 Agencia de Calidad del Ministerio de Sanidad y Consumo. Plan de Calidad del Sistema Nacional de Salud. 2007. Available from: http://www.msc.es/organizacin/sns/planCalidadSNS/ (accessed 15 February 2008).

30 Ahmann A. Guidelines and performance measures for diabetes. Am J Manag Care 2007; 13(Suppl. 2): S41-6.

31 Parchman ML, Pugh JA, Romero RL, Bowers KW. Competing demands or clinical inertia: the case of elevated glycosylated hemoglobin. Ann Fam Med 2007; 5: 196-201.

32 Wens J, Dirven K, Mathieu C et al. Quality indicators for type-2 diabetes care in practice guidelines: an example from six European countries. Prim Care Diabetes 2007; 1: 17-23.

33 Gregg E, Karter A, Gerzoff R et al. Characteristics of insured patients with persistent gaps in diabetes care services: the Translating Research into Action for Diabetes (TRIAD) study. Med Care 2010; 48: 31-7.

34 Mangione C, Gerzoff R, Williamson D et al. The association between quality of care and the intensity of diabetes disease management programs. Ann Intern Med 2006; 145: 107-16.

35 Liebl A, Mata M, Eschwège E, Board O-A. Evaluation of risk factors for development of complications in type II diabetes in Europe. Diabetologia 2002; 45: S23-8.

36 Piwernetz K, Home P, Snorgaard O et al. Monitoring the targets of the St Vincent Declaration and the implementation of quality management in diabetes care: the DIABCARE initiative. The DIABCARE Monitoring Group of the St Vincent Declaration Steering Committee. Diabet Med 1993; 10: 371-7.

37 Pischon T. Commentary: Use of the body mass index to assess the risk of health outcomes: time to say goodbye? Int J Epidemiol 2010; 39: 528-9.

38 Haslam DW, James WP. Obesity. Lancet 2005; 366: 1197-209.

$39 \mathrm{Hu}$ FB. Obesity and mortality: watch your waist, not just your weight. Arch Intern Med 2007; 167: 875-6.

40 Zhang X, Shu XO, Yang G et al. Abdominal adiposity and mortality in Chinese women. Arch Intern Med 2007; 167: 886-92.

41 I. D. F. Clinical Guidelines Task Force. Global Guideline for Type 2 Diabetes: recommendations for standard, comprehensive, and minimal care. Diabet Med 2006; 23: 579-93.

42 Phillips L, Branch W, Cook C et al. Clinical inertia. Ann Intern Med 2001; 135: 825-34.

43 Shah B, Hux J, Laupacis A et al. Clinical inertia in response to inadequate glycemic control: do specialists differ from primary care physicians? Diabetes Care 2005; 28: 600-6.

44 Grant R, Cagliero E, Dubey A et al. Clinical inertia in the management of type 2 diabetes metabolic risk factors. Diabet Med 2004; 21: 150-5.

45 Davis D, O'Brien M, Freemantle N et al. Impact of formal continuing medical education: do conferences, workshops, rounds, and other traditional continuing education activities change physician behavior or health care outcomes? JAMA 1999; 282: 867-74.

46 Martin S, Schramm W, Schneider B et al. Epidemiology of complications and total treatment costs from diagnosis of Type 2 diabetes in Germany (ROSSO 4). Exp Clin Endocrinol Diabetes 2007; 115: 495-501. 